\title{
Un método eficiente para la inducción de callos in vitro en Myrciaria dubia (Kunth) Mc Vaugh "Camu Camu"
}

\section{An efficient method for in vitro callus induction in Myrciaria dubia (Kunth) Mc Vaugh "Camu Camu"}

\author{
Ana M. Córdova ${ }^{1}$, Marianela Cobos ${ }^{1}$, Sixto A. Imán ${ }^{2}$, Juan C. Castro ${ }^{1, *}$ \\ ${ }^{1}$ Unidad Especializada de Biotecnología (UEB). Centro de Investigaciones de Recursos Naturales de la Amazonía \\ (CIRNA). Universidad Nacional de la Amazonía Peruana (UNAP). AAHH Nuevo San Lorenzo, Pasaje Los Paujiles S/N. \\ San Juan Bautista, Iquitos-Perú. \\ 2 Recursos Genéticos Vegetales. Instituto Nacional de Innovación Agraria (INIA). Iquitos-Perú. E.E.San Roque. Av San \\ Roque 209-Iquitos.
}

Recibido 09 diciembre 2013. Aceptado 14 marzo 2014.

\begin{abstract}
Resumen
Debido a la alta variabilidad en la producción de vitamina C en Myrciaria dubia "camu camu", es necesario establecer procedimientos biotecnológicos para la propagación clonal masiva de genotipos promisorios de esta especie. El objetivo fue establecer un método eficiente para inducir la formación de callos in vitro a partir de explantes de $M$. dubia. Los explantes de hojas y nudos se obtuvieron de ramas cultivadas en el laboratorio y la pulpa a partir de frutos colectados en el campo. Estos fueron desinfectados y sembrados en medio MurashigeSkoog (1962) suplementado con ácido 2,4-diclorofenoxiacético (2,4-D), bencilaminopurina (BAP) y kinetina (Kin). Los cultivos fueron mantenidos a $25 \pm 2^{\circ} \mathrm{C}$, en oscuridad por 2 semanas y posteriormente con un fotoperiodo de 16 horas luz y 8 horas de oscuridad por 6 semanas. El tratamiento con $2 \mathrm{mg} / \mathrm{L}$ de 2,4 -D y 0,1 $\mathrm{mg} / \mathrm{L}$ de BAP estimuló mayor callogénesis en los tres tipos de explantes. Los callos se generaron a partir de la primera semana (nudos), cuarta semana (hojas) y sexta semana (pulpa) y estos fueron friables (hojas y nudos) y no friables (pulpa). En conclusión, el método descrito es eficiente para inducir callos in vitro en hojas, nudos y pulpa de $M$. dubia, siendo los explantes de hojas y nudos los más idóneos para la obtención de callos.

Palabras clave: callogénesis, propagación clonal, camu camu, in vitro, Myrciaria dubia.
\end{abstract}

\begin{abstract}
Due to the high variability in vitamin C production in Myrciaria dubia "camu camu", biotechnological procedures are necessary for mass clonal propagation of promising genotypes of this species. The aim was to establish an efficient method for in vitro callus induction from explants of $M$. dubia. Leaf and knot sex plants were obtained from branches grown in the laboratory and from fruit pulp collected in the field. These were desinfected and sown on Murashige-Skoog (1962) medium supplemented with 2,4-dichlorophenoxyacetic acid $(2,4-\mathrm{D})$, benzylaminopurine (BAP) and kinetin(Kin). The cultures were maintained at $25 \pm 2^{\circ} \mathrm{C}$ in darkness for 2 weeks and subsequently with a photoperiod of 16 hours in light and 8 hours in dark for 6 weeks. Treatment with $2 \mathrm{mg} / \mathrm{L} \mathrm{2,4-D}$ and $0.1 \mathrm{mg} / \mathrm{L}$ BAP allowed major callus formation in the three types of explants. Calluswere generated from the first week (knots), fourth week (leaves) and sixth week (pulp) and these were friable (leaves and nodes) and non-friable (pulp). In conclusion, the described method is efficient for in vitro callus induction in leaves, knots and pulp of $M$. dubia, been leaves and knots explants more suitable for callus obtention.
\end{abstract}

Keywords: callogenesis, clonal propagation, camu camu, in vitro, Myrciaria dubia.

\section{Introducción}

Myrciariadubia es un frutal nativo de la región amazónica que se caracteriza por tener frutos con más de $2 \mathrm{~g}$ de vitamina $\mathrm{C}$ por $100 \mathrm{~g}$ de pulpa (Córdova et al., 2010). Asimismo, sus frutos contienen antocianinas como cianidina-3-glucósido (Villanueva et al., 2010), carotenoides como luteína (Zanatta y Mercadante, 2007; Azevedo-Meleiro y Rodríguez-Amaya, 2009) y otras sustancias con potencial uso farmacológico (Akachi et al., 2010;

\footnotetext{
* Autor para correspondencia

E-mail: juanccgomez@yahoo.es (J. Castro)
} 
Yazawa et al., 2011; Da Silva et al., 2012; Nascimento et al., 2013). Por estas cualidades los frutos de esta especie tienen gran demanda en mercados locales, nacionales e internacionales. Sin embargo, los frutos de plantaciones naturales $y$ de sembríos agrícolas presentan una amplia variación en el contenido de vitamina $C$. Análisis de frutos maduros obtenidos de 356 plantas de la colección de germoplasma de $M$. dubia del INIA (provenientes de ocho cuencas hidrográficas) muestran contenidos de vitamina $\mathrm{C}$ que varían de 0,65 a 2,53 g /100 g de pulpa (Castro et al., 2013). Esta variación representa un problema para los agricultores, porque aún no es posible garantizar la producción elevada y uniforme de vitamina $\mathrm{C}$, requisitos que exigen los mercados para el consumo directo e industrialización.

En ese sentido, es preciso contar con procedimientos de propagación clonal masiva de las plantas con las mejores cualidades. Esto es factible lograr con los métodos de la Biotecnología vegetal. Con estos métodos biotecnológicos es posible producir plantas de calidad uniforme a escala comercial, a partir de genotipos selectos y con una tasa de multiplicación ilimitada (Levitus et al., 2010). Con este propósito, se han realizado varios estudios para establecer las condiciones de propagación in vitro de $M$. dubia, pero con resultados limitados (Huaranca et al., 2000; Gonzales, 2002; Rivera, 2012) por falta de enraizamiento de las vitroplantas. Una alternativa viable para la propagación clonalin vitro de esta especie es la embriogénesis indirecta a través de la callogénesis.

Por tanto, el objetivo de esta investigación fue establecer un método eficiente para inducir la formación de callos in vitro a partir de explantes de M. dubia.

\section{Material y métodos}

\section{Colecta y transporte del material botánico}

Se colectaron frutos (verdes y pintones) y estacas entre los meses de marzo y junio del 2011, de plantas de la colección de germoplasma de M. dubia. Esta colección está constituida por 43 accesiones provenientes de ocho cuencas hidrográficas (Amazonas, Curaray, Itaya, Nanay, Napo, Putumayo, Tigre y Ucayali) de la Región Loreto y se localiza en el Centro Experimental El Dorado de la Estación Experimental Agraria San Roque-INIA, ubicado en el $\mathrm{Km} 25 \frac{1}{2}$ de la carretera Iquitos-Nauta $\left(03^{\circ} 57^{\prime} 17^{\prime \prime}\right.$ LS, 73²4'55" LO y 112 m.s.n.m.). Las muestras botánicas obtenidas fueron cubiertas con papel periódico humedecido y en bolsas de polietileno para su transporte a la Unidad Especializada de Biotecnología del CIRNA.

\section{Inducción de la callogénesis}

Las varas fueron procesadas de acuerdo a Rivera (2012) con modificaciones, que consistieron en rociarlas con $0,05 \%$ del antifúngico Benomex (metil-1-\{butilcarbamoil $\}$-2-bencimidazol- $\beta$-carbamato) cada 3 días y $0,2 \%$ del estimulante foliar Bayfolan cada 5 días desde la aparición de los brotes foliares. Las varas que mostraron crecimiento de ramas con hojas de 3 a 5 $\mathrm{cm}$ de longitud (15-20 días) fueron puestas en oscuridad por 12 horas a $25^{\circ} \mathrm{C}$. Luego las ramas se cortaron y sumergieron en 2 $\mathrm{mg} / \mathrm{L}$ de polivinilpirrodilona (PVP) estéril por 5 a 10 minutos, después se enjuagaron tres veces con agua destilada estéril. Después, se sumergieron en alcohol de $70 \%$ por 30 segundos, se enjuagaron con agua destilada estéril, se desinfectaron con $2 \%$ de $\mathrm{NaOCl}$ por 10 minutos (los frutos en $5 \%$ de $\mathrm{NaOCl}$ por 5 minutos) y enjuagaron tres veces con agua destilada estéril. Posteriormente, con un bisturí y pinzas estériles se obtuvieron los segmentos de nudos (1 cm), hojas (incluyendo la nervadura central) y pulpa de $\sim 1 \mathrm{~cm}^{2}$. Estos explantes fueron sembrados en medio Murashige-Skoog (1962) suplementado con reguladores de crecimiento y mantenidos en oscuridad por 15 días a $25 \pm 2{ }^{\circ} \mathrm{C}$. Posteriormente fueron cultivadas con un fotoperiodo de 16 horas de luz y 8 horas de oscuridad. 
Al medio básico MS se añadió 30 g/L de sacarosa, $4 \mathrm{mg} / \mathrm{L}$ de PVP y $8 \mathrm{~g} / \mathrm{L}$ de agaragar. El medio se esterilizó en autoclave (Yamato, SM 510) a $121^{\circ} \mathrm{C}, 15$ libras de presión por 15 minutos. Las citoquininas bencilaminopurina (BAP) y kinetina (Kin) fueron disueltas en 1,0 $\mathrm{N}$ de $\mathrm{NaOHy}$ la auxina ácido 2,4-diclorofenoxiacético (2,4D) en etanol al $96 \%$. Estos reguladores de crecimiento fueron esterilizados con filtros de $0,45 \mu \mathrm{m}$ y añadidos al medio básico MS atemperado a $50^{\circ} \mathrm{C}$. Los tratamientos empleados fueron: $\mathrm{T} 1$ (sin regulador de crecimiento), T2 (1 mg/L de 2,4-D + 0,1 $\mathrm{mg} / \mathrm{L}$ de BAP, proporción 10:1), T3 (1 $\mathrm{mg} / \mathrm{L}$ de 2,4-D + 0,5 mg/L de BAP, proporción 2:1), T4 (2 mg/L de 2,4-D + 0,1 mg/L de BAP, proporción 20:1), T5 (2 $\mathrm{mg} / \mathrm{L}$ de 2,4-D + 0,5 mg/L de BAP, proporción 4:1), T6 (3 mg/L de 2,4-D +
0,1 mg/L de BAP, proporción 30:1), T7 (5 $\mathrm{mg} / \mathrm{L}$ de 2,4-D + $2 \mathrm{mg} / \mathrm{L}$ de BAP, proporción 2,5:1), T8 (5 mg/L de 2,4-D + 0,1 mg/L de Kin, proporción 50:1), T9 (1,2 $\mathrm{mg} / \mathrm{L}$ de BAP).

\section{Resultados y discusión}

Los reguladores de crecimiento indujeron la formación de callos in vitro en explantes de hojas, nudos y pulpa de M. dubia, los cuales presentaron características peculiares (Figura 1). Por ejemplo, los callos generados en las hojas fueron verdes $y$ friables. Estos callos se originaron principalmente en las nervaduras y en los bordes (sitios de corte), cubriendo hasta en un 75\% la superficie del explante foliar. Este hallazgo coincide con el reporte de Otahola (2000).

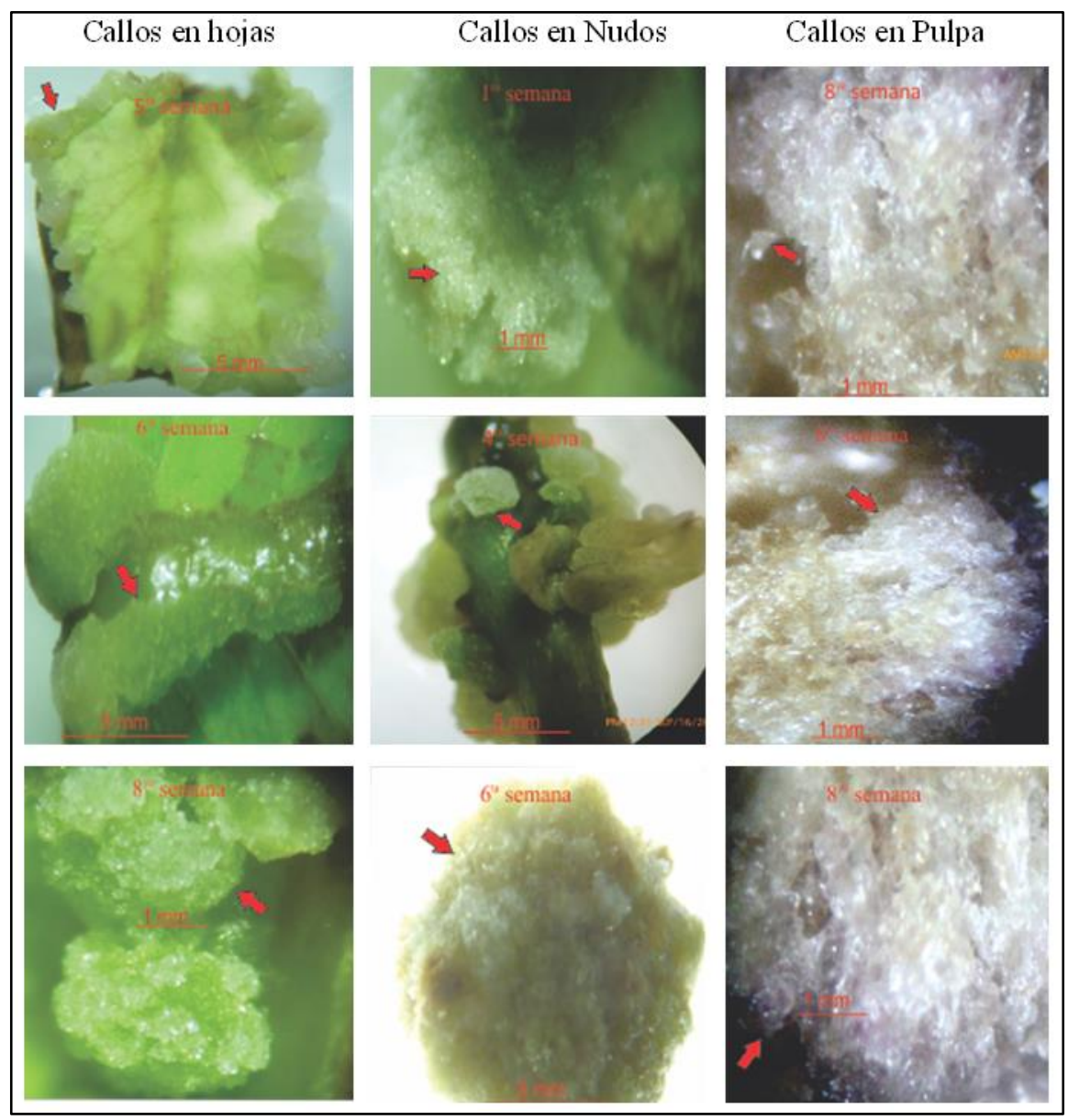

Figura 1. Callos obtenidos en explantes de hojas, nudos y pulpa de $M$. dubia tratados con 2,4-D (2 $\mathrm{mg} / \mathrm{L})$ y BAP $(0,1 \mathrm{mg} / \mathrm{L})$. 
También los callos inducidos en nudos fueron semejantes al de los explantes foliares, pero los colores variaron de blanquecino a verde claro y friables. Los callos se expresaron frecuentemente en los extremos del explante (sitios de corte) y en los sitios de inserción del peciolo, llegando a cubrir el $100 \%$ de la superficie del explante. En contraste, los explantes de pulpa generaron callos transparentes poco friables.

La mayoría de los tratamientos adicionados con reguladores de crecimiento indujeron callos in vitro en los tres tipos de explantes evaluados, pero con diferentes proporciones (Figura 2). Así, como es de esperar, los explantes de hojas, nudos y pulpa sembrados en medio sin regulador de crecimiento (T1) no generaron callos. En contraste, según el tipo, concentración y combinación de reguladores de crecimiento hasta en el $48 \%$ de los explantes se indujeron callos. Así, la callogénesis se indujo de $>70 \%$ al $100 \%$ en hojas, de $>50 \%$ al $100 \%$ en nudos (excepto los explantes del T9 que se oxidaron y no fueron viables) y en pulpa de $8 \%$ al $55 \%$. Cabe resaltar que los explantes de pulpa de frutos verdes fueron más callogénicos que los de frutos pintones. Este hallazgo coincide con Alayón et al. (2006), quienes obtienen callos tratando los explantes de pulpa de manzana por 21 días con $1 \mathrm{mg} / \mathrm{L}$ de $2,4 \mathrm{D}$ y $0,1 \mathrm{mg} / \mathrm{L}$ de BAP. Asimismo, logran inducir callogénesis de 20 a 30\% más en explantes de frutos verdes que en maduros. Es preciso destacar que la suplementación del medio Murashige y Skoog (1962) con la auxina 2,4-D y una citoquinina (Kin ó BAP) indujo la callogénesis in vitro en los tres tipos de explantes de $M$. dubia, particularmente al emplear una proporción alta de auxina:citoquinina (20:1). Estos resultados concuerdan con Roca y Mroginski (1991), quienes afirman que la callogénesis en explantes se induce en medios que contienen una alta proporción de auxina:citoquinina.

Además, Montero (2001) menciona que la auxina 2,4-D es necesaria para inducir la formación de callos. También, varios estudios muestran que los tratamientos adicionados con reguladores de crecimiento inducen la formación de callos en explantes de diversas especies de plantas, tales como Echinea purpurea (Montero, 2001), Oryza sativa (Pérez et al., 2009) у Eucalyptus globulus (Gómez et al., 2006).

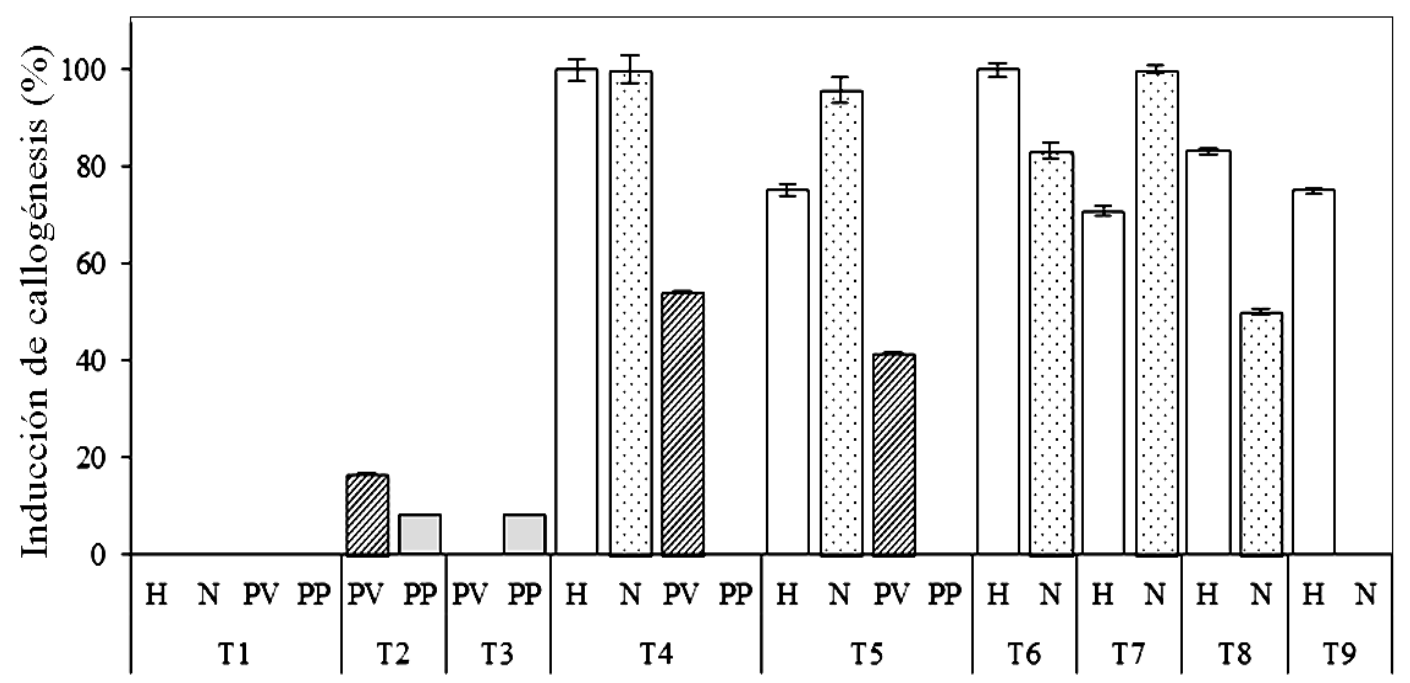

Figura 2. Inducción de callogénesis en los tres tipos de explantes de M. dubia con los tratamientos con reguladores de crecimiento evaluados. 
La inducción de la callogénesis se atribuye a los múltiples mecanismos de acción de los reguladores de crecimiento empleados. Para que las auxinas induzcan el efecto fisiológico estas deben ser transportadas desde el medio de cultivo hasta las células blanco como mencionan Taiz y Zieger (1998). Estos investigadores propusieron el modelo quimiosmótico de transporte polar de las auxinas. En este proceso las bombas de $\mathrm{H}^{+}$mantienen una gradiente electroquímica entre el citoplasma y la pared celular. Para que las auxinas induzcan el crecimiento celular estas deben unirse a receptores externos e internos, los que a la vez inducen la expresión de genes que codifican factores protéicos que aumentan la plasticidad y ablandan la pared celular. Esto tiene como efecto la dilatación de la célula, debido a la presión del agua dentro de su vacuola (presión de turgencia), de este modo continúa agrandándose hasta que la pared opone resistencia (Azcón-Bieto y Talón 2008). Por su parte las citoquininasse unen a receptores tipo histidina quinasas que activan a las histidina fosfotransferasas. Estas enzimas transmiten la señal de los receptores a los reguladores nucleares de respuesta, que pueden activar o reprimir la transcripción de genes que median las acciones fisiológicas de las citoquininas (Müller y Sheen, 2007).

El tiempo de cultivo requerido para inducir la formación de callos en los tres tipos de explantes con los distintos tratamientos adicionados con reguladores de crecimiento fue variable (Figura 3). En el caso de explantes de hojas se observaron callos a partir de la cuarta semana de cultivo (T4, T6 y T7) y desde la quinta semana todos los tratamientos indujeron callos, aunque en diferentes porcentajes. Asimismo, se evidenció que la expresión de callos se incrementó conforme transcurrió el tiempo de cultivo. La inducción de callos en nudos fue más precoz, particularmente con el T5 la callogénesis se evidenció desde los 5 días de iniciado el cultivo. La respuesta precoz que observamos con los nudos se puede atribuir al estado fisiológico de la vara yemera de donde se extrajeron los explantes. Pues esta floreció en el laboratorio y posiblemente incrementó su potencial callogénico. Este hallazgo similar al reportado por Terra et al. (2009), quienes generan callos a partir de los 7 días usando 2,4-D (5-20 mg/L). De acuerdo a Alleweldt y Radler (1962), el potencial organogénico de un explante es inversamente proporcional a su edad fisiológica. Además, Murashige (1974) indica que el estado de la planta madre y la estación durante la cual es extraído puede afectar el potencial organogenético.
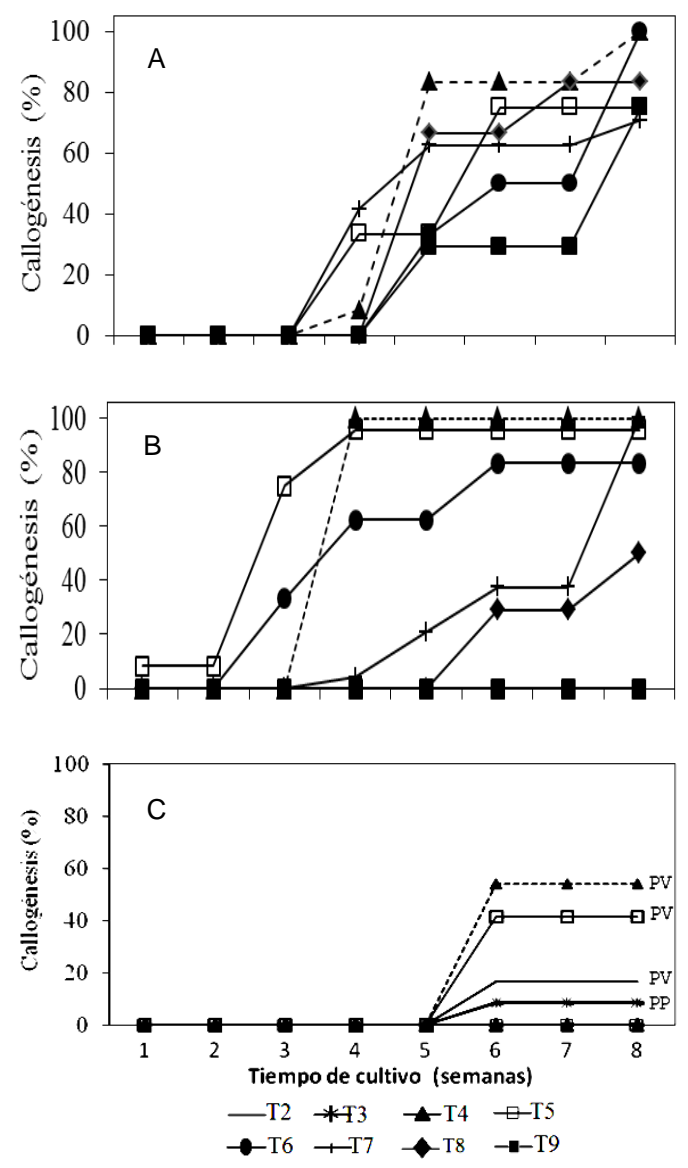

Figura 3. Inducción de callogénesis en explantes de M. dubia por los tratamientos adicionados con reguladores de crecimiento en función al tiempo de cultivo en explantes de hojas (A), nudos (B) y pulpa (C). PV: explante de pulpa de fruto verde, PP: explante de pulpa de fruto pintón. 
Respecto a los explantes de pulpa, se observó letargo en la respuesta callogénica en comparación con los explantes de hojas y nudos, de tal modo que recién a la sexta semana de cultivo se evidenció la formación de callos y la cantidad de explantes con callos no se incrementó en función al tiempo de cultivo. Esto puede deberse a que los reguladores de crecimiento empleados para inducir la callogénesis en la pulpa fueron esterilizados en autoclave, junto con el medio de cultivo. En contraste, los reguladores de crecimiento utilizados para inducir callogénesis en explantes de hojas y nudos fueron esterilizados por filtración. Lo que nos sugiere que los reguladores de crecimiento al ser sometidos a elevadas temperaturas $\left(121^{\circ} \mathrm{C}\right)$ son inactivados ya que los reguladores 2,4-D y BAP son termolábiles y kinetina es ligeramente termolábil (Gamborg y Phillips, 1995).

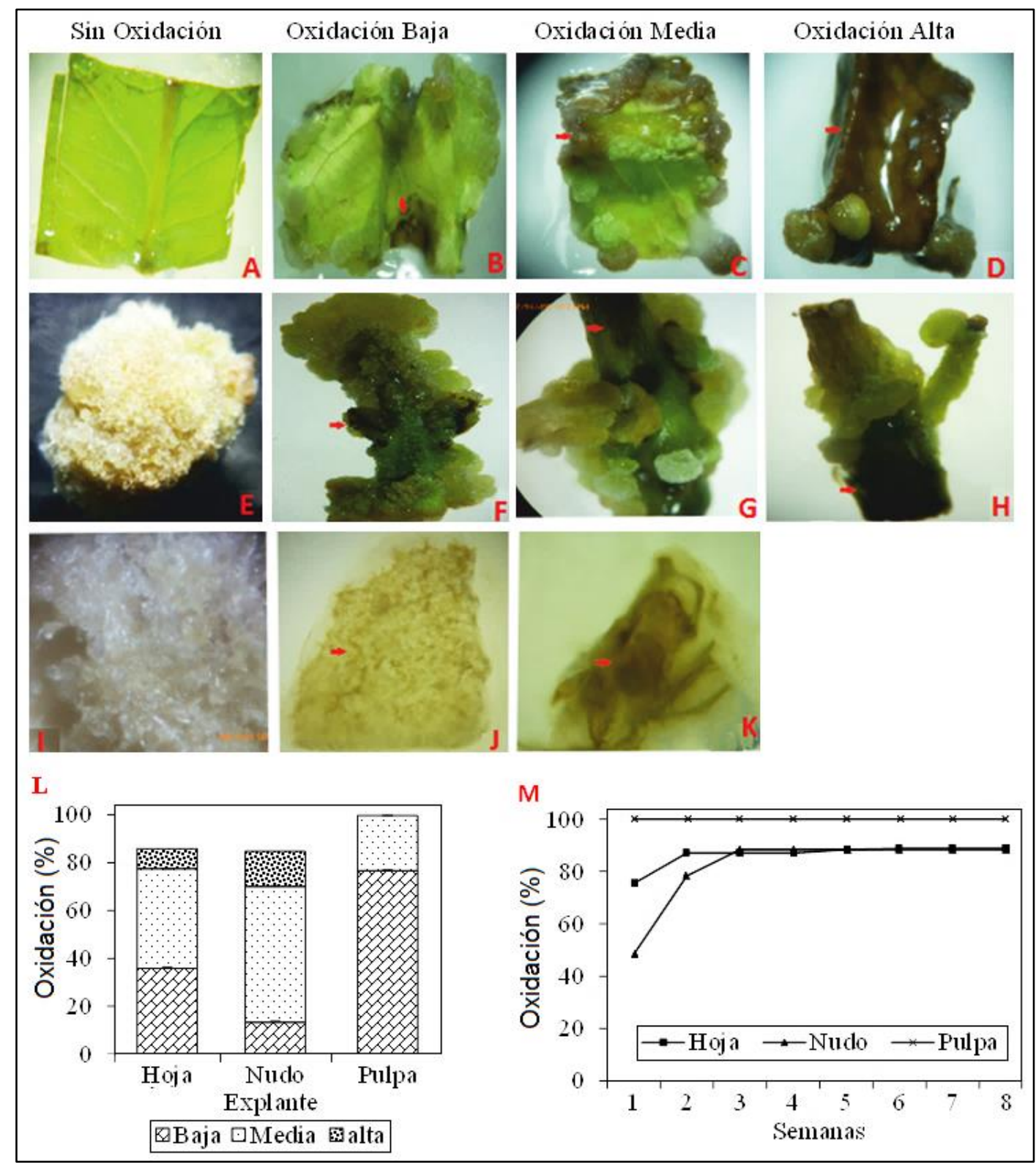

Figura 4. Explantes y callos sin oxidación y con diferentes grados de oxidación en hojas (A-D, L), nudos (E-H, L) y pulpa (I-K, L) de M. dubia. M: Porcentaje de oxidación de explantes en función al tiempo de cultivo. 
Adicionalmente, durante el cultivo los tres tipos de explantes mostraron grados de oxidación leve (baja), moderada (media) e intensa (alta) según Khalil et al. (2002) (Figura 4). Este fenómeno se manifestó por un ennegrecimiento de los explantes de hojas y nudos. Pero en pulpa por un cambio de translúcido a crema.

En las hojas y nudos se observó los tres grados de oxidación, mientras que el $70 \%$ de explantes de pulpa mostraron bajo grado de oxidación (Figura 4L). La oxidación de los explantes se evidenció principalmente en la primera semana de cultivo (Figura 4M).

Cabe indicar que en las áreas oxidadas de los explantes no se generaron los callos. Sin embargo, las áreas no oxidadas lograron expresar callos en la mayoría de los casos. La oxidación afectó principalmente a los explantes de hojas y nudos y en menor grado a los explantes de pulpa. Esto puede deberse a la exposición directa de los explantes de hojas y nudos al hipoclorito de sodio $(\mathrm{NaOCl})$, mientras que la pulpa no estuvo expuesta directamente a este compuesto oxidante. También, estas diferencias se pueden atribuir a la mayor capacidad antioxidante de la pulpa, por su alto contenido de vitamina $\mathrm{C}$, en comparación con los otros explantes (Córdova et al., 2010).

Otros estudios en cultivos in vitro del $M$. dubia también encuentran altos porcentajes de oxidación. Así, Gómez y Huaranca (1997) reportan hasta el $73,3 \%$ de oxidación de cotiledones, en especial los que sufrieron cortes, en el establecimiento in vitro de propágulos. Además, Huaranca et al. (2000), muestran altos porcentajes de oxidación en microestacas las que no pudieron ser micropropagadas. También, Gonzáles (2002) muestra hasta un 95\% de oxidación de microinjertos sometidos al cultivo in vitro en medio Murashige-Skoog (1962) completo.

El daño oxidativo observado se pueden atribuir a las especies reactivas de oxígeno y de nitrógeno producidas por los explantes de M. dubia. Según Bray et al.
(2000) y Van Staden et al. (2006), la escisión de explantes, la composición del medio, el desbalance de citoquininas / auxinas y otras condiciones estresantes al que se exponen los explantes desencadenan el estrés oxidativo y nitrosativo. Por ejemplo, los iones metálicos del medio MS como el $\mathrm{Fe}^{2+}$ pueden generar el radical hidroxilo $\left(\mathrm{OH}^{\bullet}\right)$ mediante la reacción de Fenton y provocar más daño oxidativo. Las especies reactivas mencionadas, especialmente el $\mathrm{OH}^{\bullet}$ destruye por oxidación a los lípidos, polisacáridos, proteínas y ácidos nucleicos, conduciendo a la muerte de las células del explante (Bray et al., 2000.; Mittler et al., 2004). Adicionalmente, bajo las condiciones de estrés los explantes expresan varias enzimas oxidasas como las polifenol oxidasas, fenolasas, tirosinasas y peroxidasas que al actuar sobre sus sustratos generan radicales libres que causan el ennegrecimiento y eventualmente la muerte del explante (Pompeu et al., 2008; Abdelwahd et al., 2008). Estos hechos sustentan porqué las áreas oxidadas de los explantes de las hojas, nudos y pulpa de $M$. dubia no generaron callos, a diferencia de las áreas que no han sufrido daño oxidativo, que si han producido callos.

La contaminación fue otro de los problemas que causó pérdidas de los explantes (Figura 5). Aunque, por tipo de explante se contaminaron menos del $31 \%$ (5A), estas fueron causadas principalmente por hongos $(>90 \%)$ y un menor porcentaje por hongos y bacterias. En función al tiempo de cultivo (Figura 5B), se observó que en la primera semana los explantes de hojas y nudos se contaminaron (hojas > nudos), pero no los de pulpa. En la segunda semana aumentó la cantidad de explantes contaminados de los tres tejidos. En la tercera semana, aumentaron los explantes contaminados de nudos y pulpa. A partir de la cuarta semana y hasta el final del periodo de cultivo no se evidenció contaminación de explantes de hojas y nudos. Sin embargo, en la pulpa se incrementó gradualmente hasta el final del 
periodo de cultivo. La contaminación en la primera semana en los explantes de hoja y nudo se pueden atribuir a una deficiente desinfección, porque los contaminantes (principalmente hongos) se desarrollaron a partir de los explantes. Al respecto, Verde (2009) aisló, a partir de hojas, frutos y raíces del $M$. dubia, hongos parásitos de los géneros Colletotrichum sp., Marssonina sp., Curvularia sp., Pestalotia sp., Fusarium sp. y Lasiodiplodia theobromae y tres hongos no parásitos de los géneros Fumago sp., Capnodium sp. y Dinemasporium sp. El problema de contaminación inicial no se observó en la pulpa, debido a su esterilidad y menor exposición a microorganismos contaminantes del ambiente. Las contaminaciones aparecidas en las semanas subsiguientes fueron causadas por hongos ambientales que lograron ingresar a las placas de cultivo, probablemente por las manipulaciones realizadas $y$ su insuficiente hermeticidad.

Otros trabajos realizados en la propagación in vitro del $M$. dubia también reportan problemas de contaminación microbiana, pero no indican el tipo de agente causal. En el caso de Gómez y Huaranca (1997), reportaron hasta un $66,6 \%$ de contaminación en sus cultivos. Asimismo, Gonzáles (2002) muestra altos porcentajes de contaminación (hasta 55\%) y concluye que la variable contaminación juega un papel importante para la sobrevivencia de los microinjertos del M. dubia. Además,
Rivera (2012) registra contaminación que afecta aproximadamente al $15 \%$ de sus explantes.

Es necesario señalar que el estudio realizado tuvo varias limitaciones. Porque no se evaluaron si otros explantes derivados de raíces, ápices caulinares, flores, cáscara de frutos, etc., tienen capacidad callogénica. Además, no se analizó esta capacidad en explantes obtenidos en diferentes épocas del año o estados fisiológicos de la planta donadora (como floración, fructificación). Además, no se determinó el efecto de otras concentraciones de las fitohormonas en la respuesta callogénica de los explantes.

Sin embargo, los resultados de esta investigación servirán de base para realizar futuros estudios biotecnológicos de $M$. dubia. Porque a partir de los callos obtenidos se podrá inducir, bajo ciertos tratamientos fitohormonales, la embriogénesis somática, caulogénesis y rizogénesis. Además, con estudios del transcriptoma en los procesos mencionados será posible identificar los genes responsables Asimismo, será factible realizar cultivos celulares para la obtención de diversas sustancias de interés farmacológico. También, permitirá la implementación de técnicas de mejoramiento genético con el empleo de la tecnología del ADN recombinante, estudios fisiológicos, metabólicos, genéticos, entre otros.
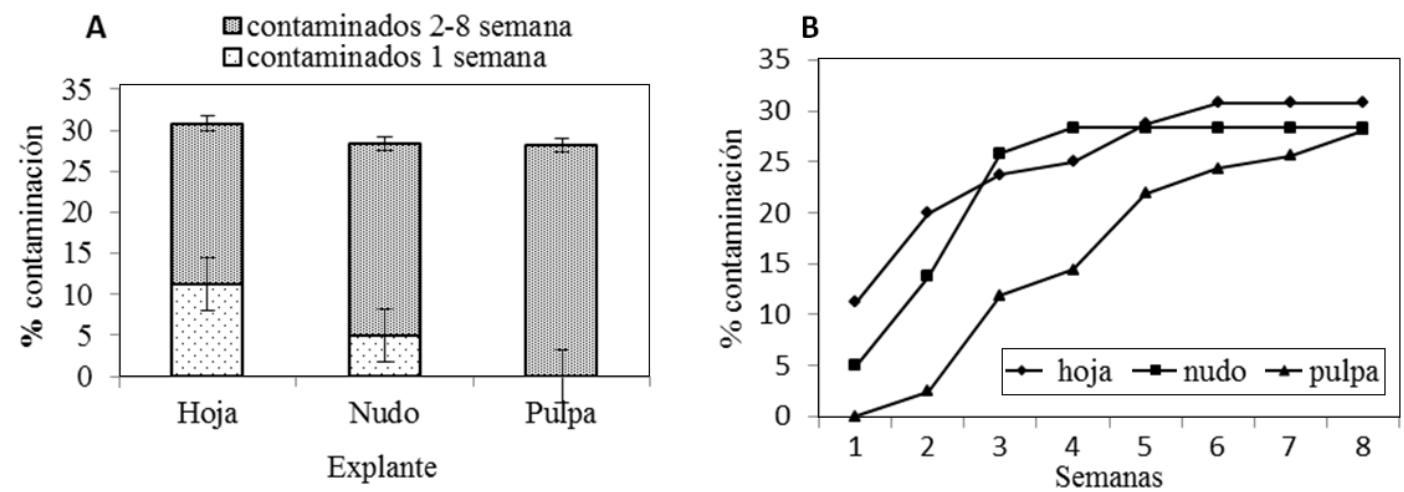

Figura 5. Porcentaje de contaminación en los tres explantes de M. dubia evaluada en las 8 semanas de cultivo. 


\section{Conclusiones}

El método descrito es eficiente para inducir callos in vitro en hojas, nudos y pulpa de M. dubia, siendo los explantes de hojas y nudos los más idóneos para la obtención de callos. $\mathrm{Y}$ el tratamiento adicionado con reguladores de crecimiento 2,4-D $2 \mathrm{mg} / \mathrm{l}+$ BAP $0,1 \mathrm{mg} / \mathrm{l}$, fue el que mejor respuesta fisiológica proporcionó a los explantes estudiados. Por lo que, con los resultados obtenidos se puede dar inicio a la inducción de la embriogénesis somática y organogénesis en Myrciaria dubia.

\section{Agradecimientos}

A la Universidad Nacional de la Amazonia Peruana (UNAP) que proporcionó los fondos para la ejecución del Proyecto "Aplicación de herramientas biotecnológicas para la clonación y obtención de líneas celulares de alto rendimiento de vitamina $\mathrm{C}$ de Myrciaria dubia (Kunth) McVaugh "camucamu". También agradecemos al Dr. Jorge Luis Marapa del Águila por facilitarnos el uso de las instalaciones y equipos de la UEB-CIRNAUNAP.

\section{Referencias bibliográficas}

Abdelwahd, R.; Hakam, N.; Labhilili, M.; Udupa, S. 2008 Use of an adsorbent and antioxidants to reduce the effects of leached phenolics in in vitro plantlet regeneration of faba bean. African Journal of Biotechnology 7: 997-1002.

Akachi, T.; Shiina, Y.; Kawaguchi, T.; Kawagishi, H.; Morita, T.; Sugiyama, K. 2010. 1-methylmalate from camu-camu (Myrciaria dubia) suppressed Dgalactosamine-induced liver injuri in rats. Biosci Biotechnol Biochem. 74(3): 573-578.

Alayón, P.; Tarragó, J.; Mroginski, L.; Pagano, E.; Sozzi, G. 2006. Obtención de callos por cultivo in vitro de pulpa de manzana cv 'Anna': Detección de actividad de Alfa-L-arabinofuranosidasa. Universidad Nacional del NORDESTE. Comunicaciones Científicas y Tecnológicas, Resumen: A-044.

Alleweldt, G.; Radler, F. 1962. Interrelationship Between Photoperiodic Behavior of Grapes \& Growth of Plant Tissue Cultures. Plant Physiol. 37(3): 376-379.

Azcon-Brieto, J.; Talon, M. (eds). 2008. Fisiología y Bioquíminca Vegetal. Editorial McGraw - Hill Interamericana. 2da Ed. Madrid.

Azevedo-Meleiro, C.H.; Rodriguez-Amaya, D.B. 2009. Qualitative and quantitative differences in the carotenoid composition of yellow and red peppers determined by HPLC-DAD-MS. J Sep Sci. 32(21): 3652-3658.
Bray, E.A.; Bailey-Serres, J.; Weretilnyk, E. 2000. Responses to abiotic stresses. In: Buchanan, B.B; Gruissem, W; Jones, R.L. eds. Biochemistry and Molecular Biology Biochemistry and molecular biology of plants. American Society of Plant Physiologists.Rockiville, USA. p. 1158-1203.

Castro, J.C.; Gutiérrez, F.; Acuña, C.; Cerdeira, LA.; Tapullima, A.; Cobos, M.; Imán, SA. 2013. Variación del contenido de vitamina $\mathrm{C}$ y antocianinas en Myrciariadubia "camucamu". Rev. Soc. Quim. Perú. 79(4): 319-330.

Córdova, A.M.; Ramírez, R.; Adrianzen, P.; Cobos, M.; Castro, J.C. 2010. Contenido de ácido ascórbico total en hojas y en diferentes estados de maduración de frutos de Myrciaria. dubia (H.B.K) McVaugh "camucamu". Loreto - Perú". Libro de resúmenes de investigaciones IX Asamblea General UNAMAZ. p18.

Da Silva, F.C.; Arruda, A.; Ledel, A.; Dauth, C.; Romão, N.F.; Viana, R.N.; De Barros Falcão Ferraz, A.; Picada, J.N.; Pereira, P. 2012. Antigenotoxic effect of acute, subacute and chronic treatments with Amazonian camu-camu (Myrciaria dubia) juice on mice blood cells. Food Chem Toxicol. 50(7): 22752281.

Gamborg, O.L.; Phillips, G.C. 1995. Plant cell tissue organ culture. Fundamental methods. SpringerVerlag. Berlin Heidelberg, pp 81-90.

Gómez, C.; Uribe, M.; Ríos, D.; Sánchez-Olate, M. 2006. Inducción de callo embriogénico en Eucalyptus globulus Labill. INCI. 31(10).

Gómez, M.; Huaranca R. 1997. Establecimiento in vitro de propágulos de camu- camu Myrciaria dubia (H.B.K) Mc.Vaugh. TESIS, Universidad Nacional De La Amazonia Peruana - Ciencias Biológicas, IquitosPerú.

Gonzales, R. 2002. Microinjertación de camu camu Myrciaria dubia (HBK) McVaugh en dos patrones y cuatro medios de cultivo Loreto-Perú. Tesis para optar el Título Profesional de Biólogo. Facultad de Ciencias Biológicas. Universidad Nacional de la Amazonía Peruana (UNAP). Iquitos-Perú.

Huaranca, R.; Diaz, F.; Lay, T. 2000. Micropropagación "in vitro" de algunas especies vegetales de interés para la Amazonia Peruana. Rev. Conoc. 6(1): 63-76.

Khalil, S.M.; Cheah, K.T.; Pérez, E.A.; Gaskill, D.A.; Hu, J.S. 2002. Regeneration of banana (Musa spp. AAB cv. Dwarf Brazilian) Via Secondary Somatic Embryogenesis. Plant Cell Rep 20: 1128-1134.

Levitus, G.; Echenique, V.; Rubinstein, C.; Hopp, E.; Mroginski, L. 2010. Biotecnología y Mejoramiento Vegetal II. Instituto Nacional de Tecnología Agropecuaria, Argentina.

Mittler, R.; Vanderauwera, S.; Gollery, M.; Breusegem, F. 2004. Reactive oxygen gene network of plants.Trends in Plant Science 9: 490-498.

Montero, W. 2001. Estudio morfogénico e histológico de Equinacea purpurea in vitro (Equinacea sp). Vicerrectoría de Investigación y extensión. ITCR. Cartago, Costa Rica. 60 p.

Müller, B.; Sheen, J. 2007. Advances in Cytokinin Signaling. Science 318:68-69.

Murashige, T.; Skoog, F. 1962. A revised medium for rapid growth and bioassays with tobacco tissue cultures. Physiologia Plantarum 15: 437-497. 
Murashige, T. 1974. Plant propagation through tissue culture. Ann. Rev. Plant Physiol. 25: 135 -166.

Nascimento, O.V.; Boleti, A.P.; Yuyama, L.K.; Lima, E.S. 2013. Effects of diet supplementation with camu-camu Myrciaria dubia (HBK) Mc Vaugh fruit in a rat model of diet-induced obesity. An Acad Bras Cienc. 85 (1): 355-363.

Otahola, V. 2000. Regeneración de plantas de parchita (Passiflora edulis y F. Flavicarpa) a partir de cultivo in vitro de discos de hojas. Rev. Bioagro 12(3): 71-74.

Pérez, M.; Hernández, C.; Teresa, M.; Delgado, M.; Armas. 2009. Expresión transitoria GUS en callos de arroz (var. J-104) mediante la optimización de las condiciones de cultivo in vitro. Rev. Colomb. Biotecnol. XI(2): 75-84.

Pompeu, G.; Gratão, P.; Vitorello, V.; Azevedo, R. 2008. Antioxidant isoemzyme responses to nickel-induced stress in tabacco cell suspension culture. Scientia Agricola 65: 548-552.

Rivera, R. 2012. Colección y establecimiento in vitro de microestacas de Myrciaria dubia "camu camu" (HBK) McVaugh. Tesis para optar el Título Profesional de Biólogo. UNAP. Iquitos - Perú.

Roca, W.; Mroginski, L. 1991. Cultivo de Tejidos en la Agricultura: Fundamentos y Aplicaciones. Centro Internacional de Agricultura Tropical (CIAT). Cali, Colombia: $143-160$.

Taiz, L.; Zieger, E. 1998. Plant Physiology. 2da ed., Sinauer Associates, Inc. Massachusetts.
Terra, E.; Faustini, G.R.; Cuzzuol.; Vilas, K.; Pinto, F.; Almeida, J. 2009. Controle da calogênese do paubrasil in vitro. Revista Arvore 33(6): 987-996.

Van Staden, J.; Fennell, C.W.; Taylor, N.J. 2006. Plant stress in vitro: the role of phytohormones. Acta Horticulturae (ISHS) - V International Symposium on In Vitro Culture and Horticultural Breeding 725: 5562.

Verde, W. 2009. Identificación y caracterización y aislamiento in vitro de hongos fitopatógenos del camu camu Myrciaria dubia (H.B.K) McVaugh en Pucallpa, Perú. Disponible en: http://www.plusformacion.com/ Recursos/r/Identificacion-caracterizacion-aislamientovitro-hongos-fitopatogenos-del-Camu-Camu. Acceso 20 marzo 2014.

Villanueva, J.E.; Condezo, L.A., Asquieri, E.R. 2010. Antocianinas, ácido ascórbico, polifenoles totales y actividad antioxidante, en la cáscara de camu-camu (Myrciaria dubia (H.B.K) McVaugh). Ciênc. Tecnol. Aliment. (Campinas) 30(Supl.1): 151-160.

Yazawa, K.; Suga, K.; Honma, A.; Shirosaki, M.; Koyama. T. 2011. Anti-inflammatory effects of seeds the tropical fruit camu camu (Myrciaria dubia). Journal Nutr, Sci. Vitaminol (Tokyo) 57(1): 104-107.

Zanatta, C.F.; Mercadante, A.Z. 2007. Carotenoid composition from the Brazilian tropical fruit camucamu (Myrciaria dubia). Food Chemistry 101(4): 1526-1532. 